Liliana Ribeiro lili.ana.s.rib@gmail.com

Madalena Pereira madaper@gmail.com

José Lucas jlucas@ubi.pt

Textile and Paper R\&D Unit, University of Beira Interior

\title{
The culture of obstacles - design for the user's experience
}

The object, which closely integrates the very definition of culture, is the alterity of the subject. Society - organized, designed, and therefore functional life - is based on the material construction and the Human being, the one who produces, lives around these same designs.

To these objects are attributed either significant or functional qualities whatever it may be it always happens within certain evaluation parameters such as space and time parameters. There is, in a theoretical radical, a sphere of historical definitions of each culture - which are easily passed to the status of tradition - products that are either artificial either from natural roots, contribute to an internal language to those to it is common. The designer stands out as the constructor of vital realities of cultures, to each object thrown on society, the producer must understand that the same design will be responsible for the transformation of the environment.

On any artifice designed, designers must respond responsibly while that may prevent commercial arteries from clogging and the culture to rewind itself. There are already some models - although almost always linked to sustainability - that open doors to alternatives pathways to the frenetic pace to which grows in this garden of objects; this paper synthetically presents the relationship between the designer and the consumer (the society) based on a communication based model.

Of, dialogic, unfinished or intersubjective, the objects may contribute to a lower obstruction in the development of culture; emphasis being placed on the user's experience.

keywords design, objects, communication, experience, culture

\section{Introduction}

This theoretical proposition studies the design in the light of communication since this second one is easily recognized on what the design inherently terminates within its field of intervention. The communication corresponds to human nature itself, every subject, even counteracting this axiom, is doomed to communicate and to construct from it the own notion of reality (realities).

With communication - which can also be viewed as behaviour - are built and sent messages that affect the lives of others around Man; as well design and its very commitment associated with practical construction of human experiences. Here, the process remains with the same frame. Merely will be renamed its integral elements. The sender will be the designer, who according to a channel - design - proceeds the sending of a message - the object - that in the end is interpreted by the receiver. The code, placed in a prominent place in understanding the meaning will be the culture that surrounds 
the entire design process. In a first instance messages are coded and the receiver is responsible for its understanding - experience.

\section{Design}

Semantically, the term 'design' emerges from a conjuncture of frauds, leading us to characterize the designer as a conspirator. In the same semantic context, Flusser (2010) identified some concepts that are directly interconnected with the word under study: machine and technique.

'Polyméchanos' is usually translated as 'crafty' by Homero when referring to Ulysses for having devised the Trojan Horse, which is a 'mechos' - a mechanism that aims to deceive, a trap, on the other hand the term is also sourced by 'magh', which can be recognized on German words 'macht' and 'mögen' (the 'artist'). Macht is power, energy and power supply.

In the same semantic context, there is another term that Flusser indicates as fundamental on the idea of design practice: technique. The word derives from the Greek 'techne', which means 'art' - and 'tekton' is the carpenter. The Latin equivalent of 'techne' is 'ars', and 'articulum' is agility; the 'Artifex', a word that represents the artist, indicates a fraud.

According to Maria Teresa Cruz (2006) we are approaching a radical transformation in the culture, an entrance in the era of 'total design'. The perception that the design is in expansive growth is offered by the obvious rise of almost all things to a level of social and cultural discourse (the design).

The principle seems very simple, early in last century the German school Bauhaus already announced an expansive ideology of design and this is one of the most impressive issues of contemporary culture. The expansive nature of design represents a world completely designed, planned and engineered by humans. Although deceitful and above all with the awareness of self-deception, the design prospers through subjects' lives and eventually changes its own existence.

To José Bragança de Miranda (2003), the acceleration in artificial artwork brought, beyond the obstructive effects on everyday experience, the impression that the technique is a kind of autonomous progress - independent - that drags us and here the mother nature is outside of the goals established by Man. The result is a greater approximation of the modern subject to technique than to nature itself. Currently this aim seems to be the motor of contemporary culture with the reinvention, design or redesign of the real/ natural world.

\section{Communication}

To Watzlawick (2002) is crucial that in the first instance is understood that for humans that we will name 'subject' in relationships - is impossible to ignore the notion of behaviour.

If it is understood that all the process flows on a objective projection, it is worth noticing that all humanly designated artificial projects correspond to the foundations from which unfolds the construction of all human existence/experience as with the reality - built with sends and receipts of messages. By association, all design is communication. 


\section{Object}

The word 'object' derives from the Latin 'objectum' and Greek 'problemá' here is likely a conflictual approach to this question because the world and culture of common stocks are filled with objects, obstacles that serve Man. Flusser (2010) finds a contradictory relationship in what it calls 'culture's dialectic', indicates that the Human being is doubly obstructed.

In the first instance we are confronted with the obstacles that we encounter in the cultural path and then by many others made to divert the first ones. In other words, the culture, the one that has already been defined as artificial, is full of objects - that based on a semantics threshold can be described as obstacles. The objects of use are mediations between those who produce them and the others, they are projects that do not lend on an objective condition, they are inter-subjective and dialogical - in the way they do communicate. Regarding the design/creation of 'stuff', designers are confronted with terms like responsibility, stability (sustainability) and subconsciously, with culture's freedom.

When the designer has to answer to the above questions may decide positively; may choose to create inter-subjective and not objective objects. The more attention the designer is on the object more easily are created shapes that difficult the passage of others to come, and here, the designer is - as Flusser says - irresponsible. If we launch a look on the current cultural situation, we can see that the set is full of objects that were irresponsibly designed (created) and where we will find a reduction of culture's manoeuvre.

According to Adorno (2000), if we try to define the subject depending on the subject, we need to understand the subjective qualities of the object, that is, understanding that they only become something since they were created by and for the subject because he wants to be challenged in its subjectivity, in his will, with objective exoticisms that fade and give place to a meaning and/or a feeling. Argues that the search for a concept that reflects the differences between subjects and objects shouldn't end in an absolute conclusion. Even the etymological self-awareness is obviously shaped by the objective notions and a highly modelled pre-patterned or designed/experiences of the subject.

In its own prison, men may perceive the social captivity itself, with it the subject perceives the capital interest on conserving the state in which things are nowadays. The objective positivism (miraculous awareness of the Object) is guided by the profit, where the focus is anything other than the thing itself because in the edge the object becomes the profit to someone else. In reference to the prosaic objective attitude, Baudrillard (1991) finds the material good's miraculous status.

The Melanesians built replicas of airplanes that they saw passing by in the sky; this way, they believed, the mysterious flying designs would lend near them. The tribe had for certain that those would be destined to go near the similar ones, the constructions that White man had access to. Thus the author presents a similarly, the current reality of the geometric places of the abundance, where the indigenous is the primitive subject that is lost in the vegetation of objects. The consumption appears as the belief in the omnipotence of designs. The bliss and satisfaction offered by opulence are equivalent to the imitations that Melanesians built to capture the planes in search of the miraculous joy implicit in objects. The difference between the reproductions of the indigenous and the current consumer is mainly seen in the effectiveness of the 'images' arriving in an obedient way to the receptor, whereas the planes never magically landed. 
Perceptibly, the artefacts - objects born of human experience and its mutant will correspond to the regulatory element of everyday life, influencing the way of living, mediating personal and social organization. They are part of our way. The "Garden of objects" blooming within society, is the stage of our experiences. It is by the recognition of the importance of this complex that Zaccai (1995) indicates the consumer sphere as the base on the search of in-depth knowledge about how these connections have devolved and became important within the project-oriented procedure.

In an attempt to redefine the aesthetics, the author takes as its starting point the assumption that the psychic consumer stands out as an extension of their individual psychic; understand that the Super-ego defines the emotional demands, the ego the rational ones and the id stands for the sensory affinities; we quickly realize that these are not individual components that can easily distinguish nor be separated, they are highly interactive pieces and each dependent from other and all must be satisfied at once.

In the traditional and technical template the designers and the marketing experts defined a triangle, but the supremacy that suggests the existence of an ego, superego and an id indicates that the triangle should be redesigned. The plane figure starts to bend as it is understood the complexity of this matter. At a certain point, and because rational, emotional and technical requirements point in several directions in a divergent way, the scheme is presented in the form of a sphere. This is what truly defines the aesthetics and the designer's role on product development. In this direction we realize that a dominant and exclusive focus on the functional aspects - functionalism - is not sufficient to understand the behaviour of the user.

In 1997, Margoli foresaw a change on the list of major concerns in the designing process; stated that adding on concerns related to the user would be a revolutionary factor in the development of pieces and that this would be a turning point, that the product's design would become a much more complex issue than ever before. Contends that the "experience" factor hasn't been had the prominent place on the product design discourse, it is believed that the incorporation of this keyword confronts designers with some questions such as the relationship between objects and users. These changes reshape the perspective directly focused on functionality to a concept of 'action'. The functionality correlates primarily with the mechanical body while the "action" is focused on the use. The idea of the experience of the object helps to emphasize the whole notion of use and Margolin argues that it helps fill the cliff that separates the producer from the user. Experience reconfigures and diverts the projective focus - centrally focused on operational and mechanical issues - to a point of view that is adjusted to human needs and activities, the objects that results of human design are not free from meaning, the are not present within a vacuum space and therefore they themselves become carriers of meaning(s). Margolin (1997) transcribes a deposition from the designer Bernhard Bükdek that he considers relevant to exemplify the subversion of experience to the mechanical operations on the product:

"The telephone set in my Office has 30 push buttons, the system is so intelligent that I can use just some two or three basic functions. I don't want to remember all (the) other(s) and I really don ' $t$ want to read the user instructions during a telephone call." (Bükdek apud Margolin, 1997: 229).

In this case the 'experience' factor becomes completely overshadowed by the capabilities 
and the multifunction of the device. Not only the sense of knowledge but also the experience (as the satisfaction) were committed in this particular episode, in result of these relationships we find that factor - which has been promoted to the top of the list - restricted. In this case we are facing a situation where the user, despite the limited use, takes advantage of the telephone function. The designers of the apparatus clearly demonstrated their own skills and knowledge regarding the technical level before the production of a multifunctional machine, however, the factor 'experience' was left behind along the production system since the designers have become negligent anticipating the relationship of the user with the system - 'action'.

\section{Conclusion}

It is concluded with clear evidence that, by communication and its internal structure method, we can thoroughly understand the integral elements in the construction of human reality and formation of the culture.

Objects, resulting from the activity of full control and folding of the chaotic nature, constitute the entrails of the very definition of culture, order, and common sets of interests. If it is by communications that the empirical truths are constructed, designs contribute to the formation of the image of what is real for the Human Being.

Besides these considerations, it is necessary to highlight the notorious implicit mediation in objects of use, in other words, acting as intermediaries between man and the world, between subject and Post modernity.

In a ratio that addresses to the interface - user, it is important to question the prominence of the user's 'experience' and how these elements can be incorporated on the development of new products capable of counterpoising to those ones responsible for a culture full of obstacles.

\section{References}

Adorno, Theodor W. (2000) Subject and Object in The Adorno Reader, edit by Brian O'Connor, Blackwell Publishers, pp. 137-153.

Baudrillard, Jean (1991) A sociedade de consumo, Edições 70, Lisboa.

Bragança de Miranda, J. (2003) "O Design como Problema", in Damásio, J. (Org.). published by Interact - Revista de Arte, Cultura e Tecnologia, nº 10, Feb. 2004 (online), Available at: interact.com.pt/category/10/, [01 April 2012]

Cruz, Maria Teresa (2006) "O artificial ou a era do Design Total" (online), Available at: http://www.cecl.com.pt/images/stories/investigacao/investigadores/maria_teresa_ cruz/o_artificial_ou_a_era_do_design_total_2006.pdf, [21 November 2011]

Flusser, Vilém (2010) Uma filosofia do design: A forma das coisas, Relógio d'água, Abril. Margolin, Victor (1997) "Getting to know the user", Design Studies, vol. 18 n 3 , Department of Art History, University of Illinois at Chicago, 935 W. Harrison St., Chicago, 3 July, USA, pp. 227-236.

Watzlawick, Paul (2002) "Pragmática da comunicação humana: Um estudo dos padrões, patologias e paradoxos da interação", (online), Available at: http://pt.scribd.com/ doc/46560810/WATZLAWICK-paul-pragmatica-da-comunicacao-humana, [20 January 2012]. Zaccai, Gianfranco (1995) Aesthetics Redefined in Discovering Design: Explorations in design studies, Victor Margolin and Richard Buchanan eds, University of Chicago Press, pp. 3-12. 
